\title{
The Development of Blended Learning Using Internet in Computer Programming and Algorithm
}

\author{
Thassanee Rodmunkong
}

\begin{abstract}
The purpose of this research is 1) To develop blended learning using internet 2) To develop the lessons via internet network in computer programming and algorithm 3) To study sample's satisfaction on blended learning using internet. The conclusions are blended learning using internet in computer programming is consisted of 2 procedures. Procedure 1) Preparation procedure, has 3 sub-procedures which are as follows; 1.1 Orientation 1.2 Grouping and 1.3 Practice. Procedure 2) Learning procedure, has 4 sub-procedures as follows; 2.1 Introduction, 2.2 Learning 2.3 Conclusion and 2.4 Posttest. The learning was divided to be $60 \%$ of a normal learning class and $40 \%$ of e-learning consecutively. The result of studying sample's satisfaction on blended learning using internet divided into 4 subjects. These are content of learning, design of teaching and learning media, interaction with e-learning and promoting learning. The average equaled 4.09 $(\mathrm{SD}=\mathbf{0 . 5 3})$ in high level.
\end{abstract}

Index Terms-Internet, blended learning, computer programming and algorithm.

\section{INTRODUCTION}

In the present education, Information and communication Technology has been applied for promoting learning of students which technology can be the result of learning management by students have ability to learn and develop themselves, and moreover, students are the most important. Learning management process is to promote students to develop themselves naturally with full effort. The teachers are responsible for giving advice, and explaining purposes and learning methods [1]. And in category $9^{\text {th }}$ of National Education Act, it mentioned that Technology for learning can be applied for teaching and learning to promote learning of students leading to self-knowledge acquisition throughout whole life [2] including policy of Information and communication Technology. In 2011 - 2020 of Thailand, strategies of education [3], supported and promoted to apply for information technology in teaching and learning, were determined to enhance potential of learning in a normal class, which led to new teaching and learning management styles e.g. using computer to support sharing learning management via internet network; e-learning, blended learning leading to sense of community more than learning in normal class environment and fully online learning [4].

Information Technology is a measuring instrument to gather data, information, knowledge presentation and

Manuscript received March 10, 2014; revised May 14, 2014.

Thassanee Rodmunkong is with the Faculty of Education, Rajabhat Rajanagarindra University, Thailand (e-mail: thassanee30@gmail.com). displaying by using tool systems — data, picture, sound, motion and video. It can create interaction system and lead to accomplishment of new learning period [5]. In addition, knowledge construction via information technology is also measuring instrument to support students to be enthusiastic, find new knowledge, enhance skills of perception, analysis and synthesis systematically. Design and creation knowledge need to create new lessons which are important and accompany with appropriateness such as reaction, freedom of distance and time, ability to approach all places and all time, control of activities and convenience of using [6].

Blended learning is learning process of students in blending between new knowledge and old knowledge by using grouping of a normal class process and information technology process to exchange views via conversation and exchanging experiences of learning from groups without any help from knowledgeable persons or books. The students will be able to create new things themselves [7].

Computer programming and Algorithm which the students should study, is a subject in curriculum of bachelor's degree in Computer Education, Rajabhat Rajanagarindra University which is basic knowledge of Algorithm, elements and functions of hardware and software, types of computer language, principles of program writing and program processing, program writing and program development methods, flowchart writing, analysis and design of Algorithm in sequential decision, repetition, modular and recursion. Only studying in a normal class is not sometimes enough. Self-study and program writing practice are needed to enhance students' skill and proficiency for related subjects in Computer Education. Therefore, applying information technology to promote teaching and learning management is one of choices of learning and communication between students and teachers by anywhere and anytime.

\section{PROPOSES OF STUDY}

\section{A. Majority Objectives}

1) To development of blended learning using internet in Computer Programming and Algorithm.

\section{B. Minority Objectives}

1) To synthesize conceptual framework to Development of blended learning using internet Model in Computer Programming and Algorithm.

2) To develop main lesson of Computer Programming and Algorithm via internet network.

3) To study sample's satisfaction on blended learning using internet. 


\section{RESEARCH FRAMEWORK}

Conceptual Framework of The Development of Blended Learning Using Internet in Computer Programming and Algorithm can be shown in Fig. 1.

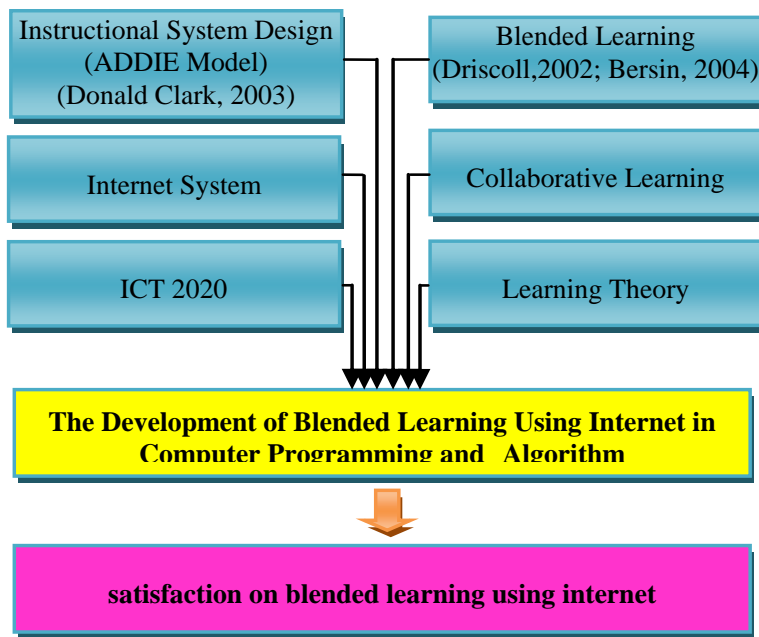

Fig. 1. Conceptual framework of the development of blended learning using internet in computer programming and algorithm.

\section{SCOPE OF STUDY}

\section{A. Population and Sample}

Population represented 65 persons of university students majored in Computer Education, Faculty of Education, Rajabhat Rajanagarindra University who registered in Computer Programming and Algorithm as a major subject in second semester of 2013.

Sample represented 32 persons undergraduate students in Computer Education, Faculty of Education, Rajabhat Rajanagarindra University who registered in Computer Programming and Algorithm as a major subject in second semester of 2013 selected by purposive sampling.

\section{B. Study Variables}

Independent variable represented a lesson running on internet network system in Computer Programming and Algorithm.

Dependent variable represented the survey result of sample's satisfaction on blended learning using internet in Computer Programming and Algorithm.

\section{METHODOLOGY}

The Development of Blended Learning Using Internet in Computer Programming and Algorithm Can Divide into Four Stages as Follows

Stage 1: To synthesize conceptual framework to Development of blended learning using internet in Computer Programming and Algorithm, The majority conceptual of this research consists of Instructional System Design, Internet System, ICT2020, Blended Learning, Collaborative Learning and Learning Theory.

Stage 2: To develop blended learning using internet in Computer Programming and Algorithm through analysis and synthesis of document and research which focuses on element, process and system approach and demonstrate relation according to design process of teaching and learning system ADDIE Model.

Stage 3: To develop Computer Programming and Algorithm lesson through internet network system by applying teaching and learning system of Moodle.

Stage 4: To study sample's satisfaction on blended learning using internet in Computer Programming and Algorithm.

Instruments of this research are a lesson running on internet network in Computer Programming and Algorithm and questionnaire of sample's satisfaction on blended learning using internet divided into 4 items as follows; content, teaching and learning design, e-learning interaction, and promoting learning. The type of used questionnaire is rating scale complies with 5 levels of Likert scale.

Statistics of result analysis of sample's satisfaction on the lesson is percentage, average $(\bar{x})$, and standard deviation (S.D.).

\section{RESEARCH CONCLUSION}

Conclusions of the study are as follows:

1) The result of blended learning using internet development in Computer Programming and Algorithm is show as Fig. 2.

2) The result of develop main lesson of Computer Programming and Algorithm via internet network is show as Fig. 3 - Fig. 8.

3) The result of study in sample's satisfaction on blended learning using internet.

The result of study in sample's satisfaction on blended learning using internet divided into four subjects. These are contents of learning, design of teaching and learning media, interaction with e-learning and promoting learning. Samples were satisfaction on blended learning using internet was at the high score, averaged at $4.09(\mathrm{SD}=0.53)$ Prioritizing average scores from maximum to minimum, the result is interaction with e-learning equaled $4.13(\mathrm{SD}=0.57)$, content of learning equaled 4.11 ( $\mathrm{SD}=0.55)$, promoting learning equaled $4.11(\mathrm{SD}=0.58)$ and design of teaching and learning media equaled $4.07(\mathrm{SD}=0.56)$ respectively.

- Interaction with e-learning Average scores prioritized from maximum to minimum are as follows; students co-worked with their assignment and helped each other averaged at $4.25(\mathrm{SD}=0.67)$, Blending learning between learning via internet network and learning in a normal class averaged at $4.21(\mathrm{SD}=0.66)$, and teachers helped students such as solving problems in sudden averaged at $4.16(\mathrm{SD}=0.68)$.

- Content of teaching and learning Average scores prioritized from maximum to minimum are as follows; used media is modern and up-to-date averaged at 4.22 $(\mathrm{SD}=0.79)$, purpose of subject is clear averaged at 4.19 ( $\mathrm{SD}=0.64)$, content is interesting and useful for teaching and learning averaged at $4.16(\mathrm{SD}=0.68)$.

- Promoting learning This can be prioritized from maximum to minimum as follows; e-learning can help students to learn anywhere and anytime averaged at 4.41 ( $\mathrm{SD}=0.84$ ), e-learning is learning exchange of each other and lead to learn faster averaged at 4.25 (SD = 
0.67), and e-learning is cooperative learning process and making relationship between each other averaged at $4.06(\mathrm{SD}=0.80)$.

- Design of teaching and learning media This can be prioritized from maximum to minimum as follows; the list of high satisfaction is categorizing the content averaged at $4.19(\mathrm{SD}=0.59)$, media on internet network is easy to use averaged at $4.13(\mathrm{SD}=0.79)$, color and size of text, which is easy to read and interesting, are useful for submitting assignment by uploading files on website and design for presentation in a kind of multimedia (picture, sound, text, video and etc.). There are 3 items which have an equal average; 4.09 (SD = $0.64,0.82$, and 0.82 ).

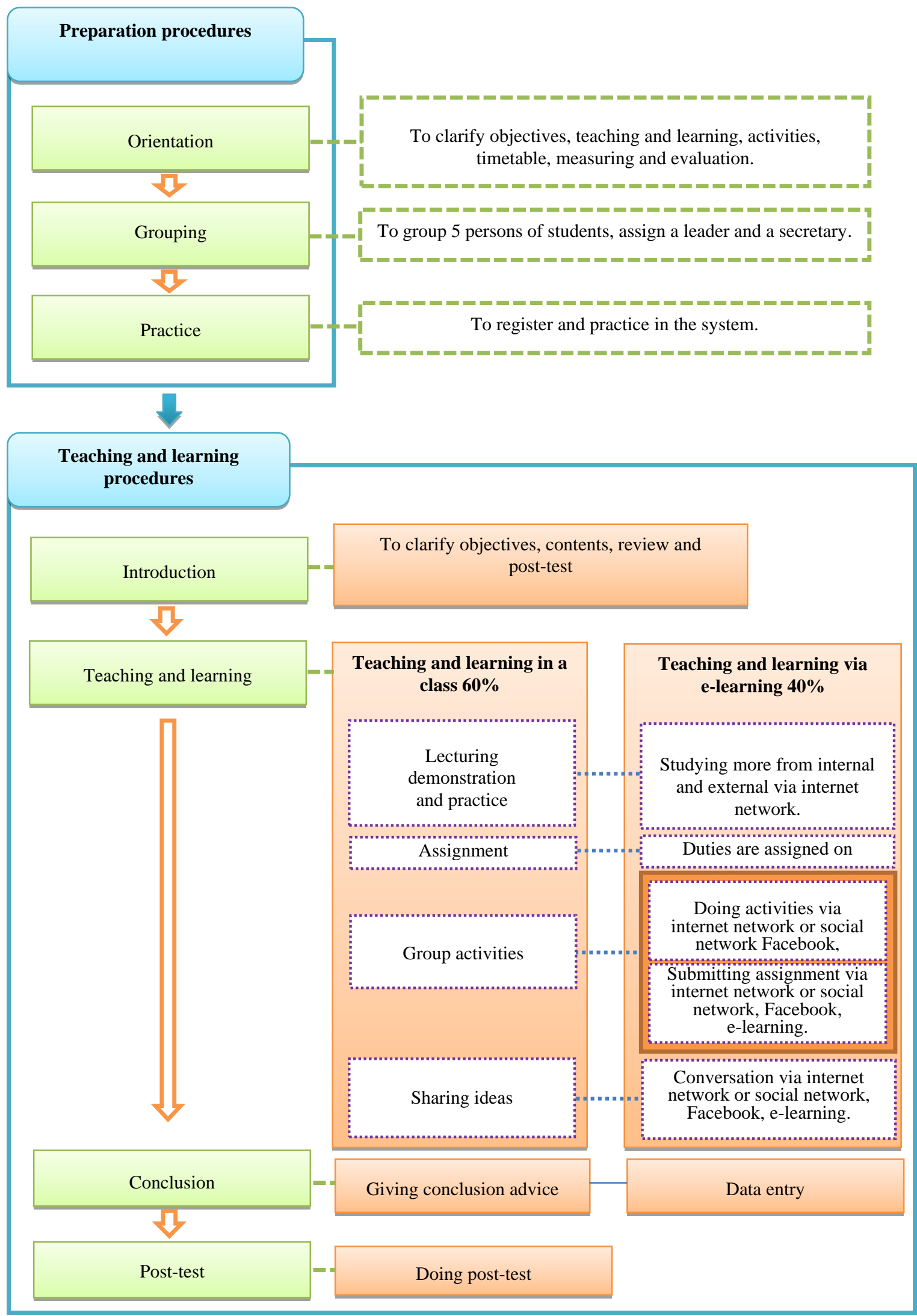

Fig. 2. The display of blended learning using internet in computer programming. 


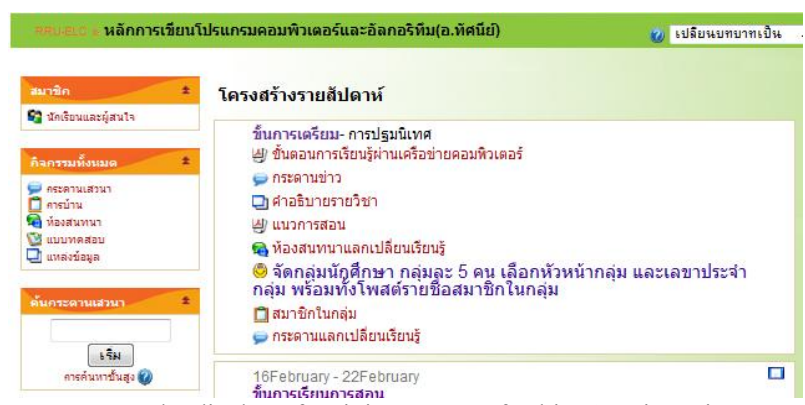

Fig. 3. The display of activity system of subject's orientation.

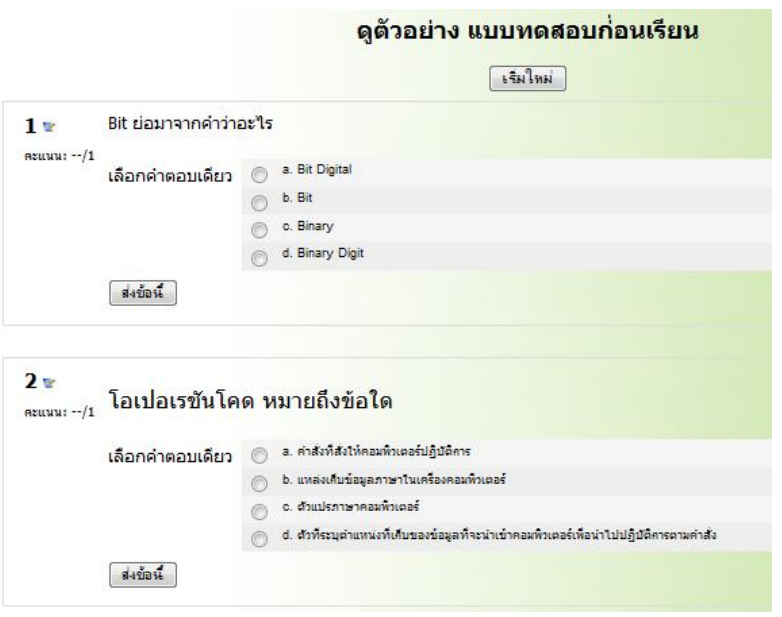

Fig. 4. The display of pretest and posttest.

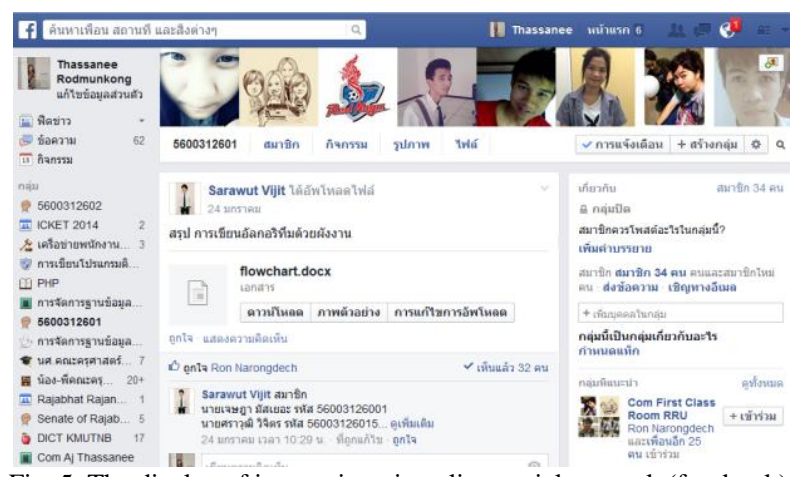

Fig. 5. The display of interaction via online social network (facebook).

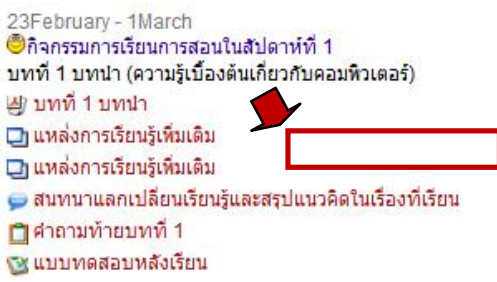

Q3 แบบทดสอบหสังเรียน

Fig. 6. The display of internal learning source connection system.

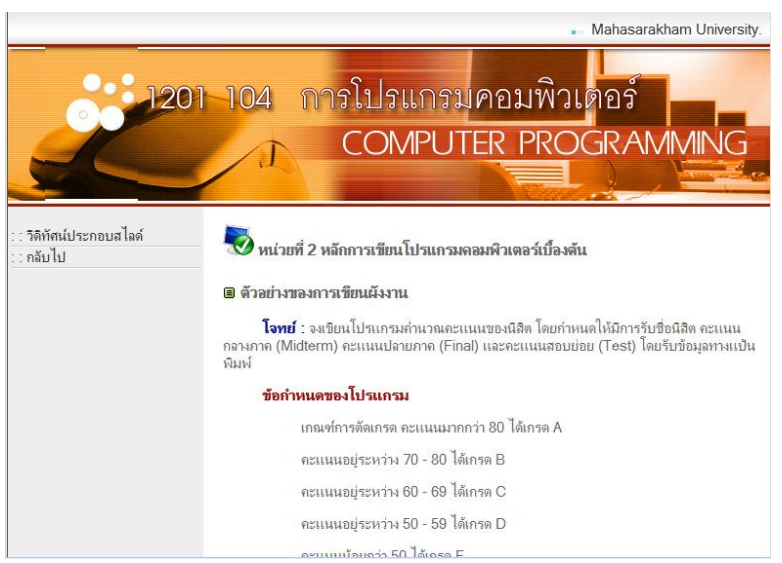

Fig. 7. The display of e-learning source.

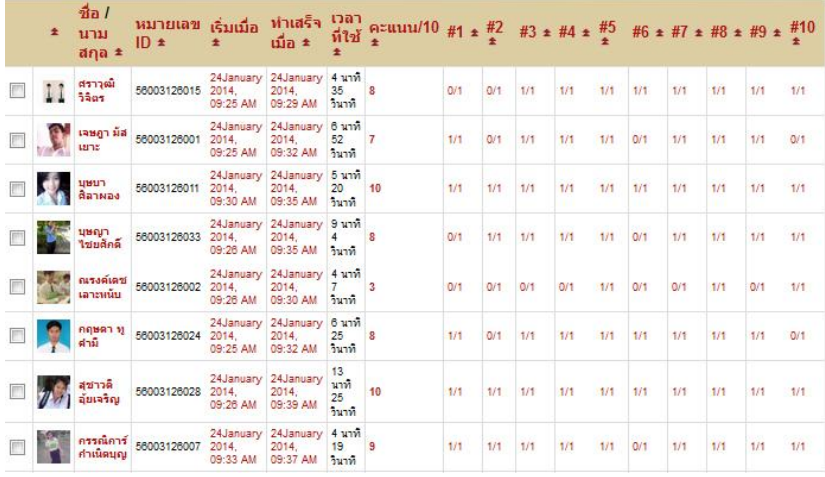

Fig. 8. The display of posttest scores.

\section{DISCUSSION}

From the development of blended learning using internet model in computer programming and Algorithm, and applying developed lessons with sample, it can be discussed as follows;

\section{A. Interaction with e-Learning}

In students opinion, this learning makes students cooperate and help each other in their assignment by helping from teacher via internet network immediately. This result corresponds with the research [8] which is the research in learning management with blended teaching model in Language, Media, Innovation and information Technology for Teacher. The research was found that nowadays information technology changes old style teaching and learning model, lecture method, to be teaching applied information technology helping for search engine and e-learning. This is for online teaching integration and face-to-face learning, which qualifications are as follows; 1) Students have interaction and cooperation to each other deeply 2) There is interaction in relationship of each other in groups. It leads to good cooperative work. And technology is applied for both before and after learning. In addition, this research also corresponds with the research [5]. The research was found that blended learning using internet makes students have sense of community more than learning in normal class environment and e-learning (fully online).

\section{B. Learning Contents}

The sample had high satisfaction with learning integrated between e-learning model and teaching in normal class. It was shown that developed learning model is up to date media which clearly defines objectives and provides interesting and useful contents in accordance with [9] who mentioned advantages of e-learning that it is convenient and flexible to edit or update information because teachers or e-learning creators can reach information no matter where they live. Moreover, students can learn anywhere and anytime.

\section{Promoting Learning}

Learning on internet network makes students learn easily in anywhere and anytime. Knowledge will be exchanged among students through cooperative learning process. It can also make relationship between each other. Blended learning using internet is then learning process of students to integrate between new acquired knowledge and prior knowledge by using grouping of a normal class process and information 
technology process to exchange views via conversation and exchange experiences of learning from groups without any help from knowledgeable persons or books. The students will be able to create new things themselves [7].

\section{Designing Educational Media}

In students' opinion, the internet network media providing optimal font size and interesting color which is easy to learn, uploading files on website which is a choice for students to save time in educational process and multimedia presentation which is used in accordance with the research [10] who studied in topic of "A Study of Priority Needs Index for Learning and Teaching Via Internet System of Rajabhat Rajanagarindra University". The result revealed that the most essential educational management is offering students an opportunity to participate in learning activity management, developing self-knowledge acquisition skill, prioritizing from easy to difficult contents properly and presentation by using multimedia.

\section{SUGGESTIONS FOR FURTHER STUDIES}

1) Developed style can be tested with other subjects and be adjusted the methods of learning to match with students of each group.

2) Teaching and learning style should be developed in improving analysis skill and advanced thinking.

3) Teaching and learning media in new patterns which is now popular should be applied in teaching and learning.

\section{REFERENCES}

[1] Ministry of Education, National Education Act B.E.2542, Bangkok, Thailand, 1999.

[2] Office of the Higher Education Commission, National Education Act B.E.2542 and Amendments (Second National Education Act B.E. 2545(2002), Bangkok, Thailand, 2000.
[3] Ministry of Information and Communication Technology, National ICT Policy Framework 2011-2020, Bangkok Thailand, 2011.

[4] Rovai and Jordan, "Blended learning and sense of community: A comparative analysis with traditional and fully online graduate courses," International Review of Research in Open and Distance Learning, pp. 1-13, vol. 5, Athabasca University, 2004.

[5] Ministry of Education, Handbook for develop learning materials, Bangkok, Thailand, 2002.

[6] Y. Puwan, "The application of education technology," presented at Seminar Roles and Direction of Technology, Kasetsart University, 2005.

[7] B. L. Smith and J. T. MacGregor, "What is collaborative learning?" in A. S. Goodsell, M. R. Maher, and V. Tinto, Eds., Collaborative Learning: A Sourcebook for Higher Education. National Center on Postsecondary Teaching, Learning, \& Assessment, Syracuse University, 1992.

[8] M. Thongsukdee and S. Chinjai. (August 2010). Learning management with blended teaching model in Language, Media, Innovation and information Technology for Teacher. Chaopraya Univerity. [Online] Available: http://office.cpu.ac.th/researchoffice

[9] P. Charuwatathik. (November 2007). The benefits of e-learning. Songkla University. [Online]. Available: http://share.psu.ac.th/blog/e-learning/1200

[10] T. Rodmunkong and N. Jeerungsuwan, "A Study of priority needs index for learning and teaching via internet system of rajabhat rajanagarindra university," Journal of Education, Faculty of Education Rajabhat Maha Sarakham University, vol. 10, no. 1, pp. 107-114, January-June 2013.

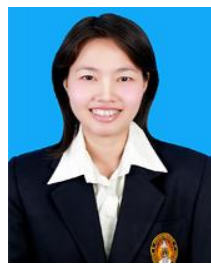

Thassanee Rodmunkong was born in Chachoengsao Province, Thailand, in 1979. She received the M.Sc. in information technology from Burapha University, Thailand. Currently she is studying in doctoral program information and communication technology for education, Faculty of Technical Education, King Mongkut's University of Technology North Bangkok (KMUTNB). She is an instructor of computer education program, Faculty of Education, Rajabhat Rajanagarindra University, Thailand. Her interesting topics are cloud computing, management information system, computer assisted instruction, information and communication technology. 